\title{
A Quantitative Review of Tebuconazole Effect on Fusarium Head Blight and Deoxynivalenol Content in Wheat
}

\author{
P. A. Paul, P. E. Lipps, D. E. Hershman, M. P. McMullen, M. A. Draper, and L. V. Madden
}

First, second, and sixth authors: Department of Plant Pathology, The Ohio State University, Ohio Agricultural Research and Development Center, Wooster 44691; third author: Department of Plant Pathology, University of Kentucky, Princeton 42445; fourth author: Department of Plant Pathology, North Dakota State University, Fargo; and fifth author: Plant Science Department, South Dakota State University, Brookings 57007.

Accepted for publication 31 August 2006.

\section{ABSTRACT}

Paul, P. A., Lipps, P. E., Hershman, D. E., McMullen, M. P., Draper, M. A., and Madden, L. V. 2007. A quantitative review of tebuconazole effect on Fusarium head blight and deoxynivalenol content in wheat. Phytopathology 97:211-220.

A meta-analysis of the effect of tebuconazole (e.g., Folicur 3.6F) on Fusarium head blight and deoxynivalenol (DON) content of wheat grain was performed using data collected from uniform fungicide trials (UFTs) conducted at multiple locations across U.S. wheat-growing regions. Response ratios (mean disease and DON levels from tebuconazole-treated plots, divided by mean disease and DON levels from untreated check plots) were calculated for each of 139 studies for tebuconazole effect on Fusarium head blight index (IND; field or plot-level disease severity, i.e., mean proportion of diseased spikelets per spike) and 101 studies for tebuconazole effect on DON contamination of harvested grain. A randomeffects meta-analysis was performed on the log-transformed ratios, and the estimated mean $\log$ ratios were transformed to estimate the mean (expected) percent control for IND $\left(\bar{C}_{I N D}\right)$ and DON $\left(\bar{C}_{D O N}\right)$. A mixedeffects meta-analysis was then done to determine the effects of wheat type (spring versus winter wheat) and disease and DON levels in the controls on the log ratios. Tebuconazole was more effective at limiting IND than DON, with $\bar{C}_{I N D}$ and $\bar{C}_{D O N}$ values of 40.3 and $21.6 \%$, respectively. The efficacy of tebuconazole as determined by the impact on both IND and DON was greater in spring wheat than in winter wheat $(P<$ 0.01 ), with a $13.2 \%$ higher $\bar{C}_{I N D}$ and a $12.4 \%$ higher $\bar{C}_{D O N}$ in spring wheat than in winter wheat. In general, $\bar{C}_{I N D}$ and $\bar{C}_{D O N}$ were both at their lowest values (and not significantly different from 0 ) when mean IND and DON in the controls, respectively, were low ( $\leq 2 \%$ for IND and $<1 \mathrm{ppm}$ for DON). $\bar{C}_{I N D}$ was $25 \%$ higher in studies with mean IND between 2 and $15 \%$ than in studies with mean IND $\leq 2 \%$, whereas $\bar{C}_{D O N}$ was $28.8 \%$ higher in studies with mean DON between 1 and $10 \mathrm{ppm}$ than in studies with mean DON $<1 \mathrm{ppm}$. The between-study variance was significantly greater than $0(P<0.01)$, indicating considerable (unexplained) variability in percent control.

Additional keywords: random-effects models, mixed-effects models, effect size, Fusarium graminearum, Gibberella zeae, wheat scab.
Fusarium head blight of wheat (Triticum aestivum L.), caused primarily by Fusarium graminearum Schwabe (teleomorph: Gibberella zeae (Schwein.) Petch), was first described during the latter part of the 19th century (2). Since then, several epidemics of varying intensities and associated yield losses have been reported throughout the world (66). Recent outbreaks of Fusarium head blight in North America have been attributed to widespread adoption of conservation tillage practices, inadequate crop rotation, and occurrence of disease-conducive weather conditions during the period of greatest host susceptibility (flowering through soft dough) $(3,38)$.

The reemergence of Fusarium head blight in the early 1990s mobilized researchers and agribusiness leaders throughout wheatgrowing regions to collaborate in multi-state projects in an effort to better understand this disease and to minimize its detrimental impact on the wheat and barley industries. The collaborative effort led to the formation of the U.S. Wheat and Barley Scab Initiative (USWBSI, East Lansing, MI). Through this organization, researchers from various wheat-growing states have been

Corresponding author: L. V. Madden; E-mail: madden.1@ osu.edu

* The $\boldsymbol{e}$-Xtra logo stands for "electronic extra" and indicates that the online version contains a Table, not included in the print version, that shows information about each individual study used in the meta-analysis.

DOI: 10.1094/PHYTO-97-2-0211

(C) 2007 The American Phytopathological Society conducting similar experiments, using standard protocols, to study various aspects of the $F$. graminearum-wheat pathosystem. Among the many collaborative research efforts currently in progress are uniform fungicide trials (UFTs) designed to evaluate fungicide effectiveness in managing Fusarium head blight and deoxynivalenol (DON), a mycotoxin produced by $F$. graminearum.

Apart from these UFTs, several individual studies have investigated the effects of different fungicides on Fusarium head blight and DON $(18,26,36,42,44,58)$. In these studies, fungicide application generally reduced the level of Fusarium head blight intensity in treated plots relative to untreated plots; however, the magnitude of this reduction varied among studies. Similarly, there have been conflicting reports on fungicide effects on DON accumulation in wheat. In some studies, fungicide treatments led to a reduction in DON below levels observed in untreated plots $(5,18,21,26,42,58)$. In others there was no significant effect of fungicide application on DON accumulation $(36,39,49)$, yet in other studies conducted under both field and greenhouse conditions, DON levels were reported to be higher (sometimes significantly so) in fungicidetreated plots than in the untreated check plots $(16,27,62,64,65)$.

In the United States, the effectiveness of tebuconazole, one of the most widely advocated and tested products for Fusarium head blight and DON management, is being evaluated through UFTs. Although standard protocols generally have been followed, fungicide efficacy has varied from one year to the next and among test locations $(24,54)$. Tebuconazole does not have a federal registration at this time for application to wheat for Fusarium head blight 
management. However, due to several outbreaks of Fusarium head blight over the last 10 to 15 years, and the absence of a more efficacious U.S. Environmental Protection Agency-registered fungicide, tebuconazole (Folicur 3.6F) has been granted an emergency exemption (Section 18) to manage Fusarium head blight and DON in one or more states since 1998. This exemption requires annual registration, and each time state registration is done, the overall effectiveness of tebuconazole comes into question (25). Thus, a quantitative review of the effectiveness of tebuconazole is warranted. Such a review can be accomplished through meta-analysis.

Meta-analysis, defined as the quantitative synthesis of the results from multiple individual studies (55), is regarded as an objective approach for integrating and interpreting results and drawing conclusions from multiple studies $(28,33)$. It is also an approach that allows the investigator to evaluate study-specific characteristics likely to influence relationships and treatment effects $(28,33)$. The quantitative research synthesis being reported herein was performed using data collected from UFTs conducted at multiple locations across U.S. wheat-growing regions. The objectives of this investigation were (i) to determine the overall effectiveness of tebuconazole in reducing Fusarium head blight and DON and (ii) to determine whether the effectiveness of this product was influenced by wheat type, disease level, and DON level. A preliminary summary of UFTs from 1998 to 2003 has been published (25). Since then, additional data have been collected from several states. Here we report on a meta-analysis of data from all UFTs.

\section{MATERIALS AND METHODS}

Uniform fungicide trials. Between 1998 and 2005, winter and spring wheat fungicide trials (the UFTs of the USWBSI), were conducted in fields across the U.S. wheat-growing region. Data from these trials and an additional nine trials conducted with the same protocols between 1995 and 1997 (prior to the establishment of the national UFTs, but which served as the basis for the national UFTs) were considered in this investigation. For brevity, we refer to all of these analyzed studies as the UFTs. Each year, trials generally were conducted according to a standard protocol in terms of types of treatments: different fungicides and fungicide application rates, separately or in combination with fungicide application timings; nozzle configuration; and wheat cultivar susceptibility. The specific fungicide treatments varied from year to year and the number of treatments ranged from five and nine, although in any given year, the same minimum set of core treatments was used in each study. An untreated check was used as reference in each study. In all studies, $38.7 \%$ tebuconazole (Folicur 3.6F) was applied as one of the treatments, at a rate of $292 \mathrm{ml} \mathrm{ha}^{-1}$ (4.0 fluid oz. acre ${ }^{-1}$ ) plus $0.125 \% \mathrm{vol} / \mathrm{vol}$ of the nonionic surfactant Induce (Helena Chemical Company, Collierville, TN). In most cases tebuconazole was applied at early flowering (Feeke's plant growth stage 10.5.1 [30]) using $\mathrm{CO}_{2}$ pressurized sprayers, equipped with Twinjet XR8002 nozzles or paired XR8001 nozzles, mounted at an angle $\left(30\right.$ or $\left.60^{\circ}\right)$ forward and backward.

Treatments were laid out in a randomized complete block design, with four (and occasionally five) replicate blocks. Planting and crop production practices varied from trial to trial in accordance with standard agronomic practices for each location. Details can be found in individual trial reports published in the proceedings of the annual forum of the USWBSI and available online. A susceptible cultivar, appropriate for the location, was used in each study. To enhance disease development, plots were either planted into corn or wheat residue, or artificially infested with $F$. graminearum-infested kernels, to supply ample inoculum for infection. Plots generally were mist-irrigated as a means of enhancing production of, and infection by, fungal inocula. In each plot of each trial, Fusarium head blight index (IND; also known as plot or field severity) was either quantified directly as the mean percentage of diseased spikelets per spike or estimated from disease incidence and diseased-head severity as previously described (41). IND could also be estimated directly from incidence using a nonlinear statistical model $(53,71)$. DON was quantified (in parts per million) after harvest as the amount of DON per unit weight of a bulked sample of ground kernels, as described by Hart et al. (19). DON analyses were done at one of the two USWBSI-funded DON testing laboratories. There were 66 winter wheat and 73 spring wheat studies with IND reported, and 60 winter wheat and 41 spring wheat studies with DON reported.

Quantitative synthesis of tebuconazole effect across trials. The levels of disease and DON in tebuconazole-treated plots relative to the levels in untreated check plots were used to evaluate the efficacy of tebuconazole treatment in each study. Mean DON and mean IND from tebuconazole-treated plots and untreated check plots were collected from each study and used to estimate the response ratio $(R)$ as

$$
R=\frac{\bar{X}_{\text {Treated }}}{\bar{X}_{\text {Check }}}
$$

where $\bar{X}_{\text {Treated }}$ is mean DON or IND from plots treated with tebuconazole, and $\bar{X}_{\text {Check }}$ is mean DON or IND from the untreated check plots. The ratio is a useful variable for quantifying the proportionate change in a response that results from an experimental manipulation (such as a fungicide application) (20). $R$ is directly related to the percent control $(C)$ of IND and DON as

$$
C=\frac{\bar{X}_{\text {Check }}-\bar{X}_{\text {Treated }}}{\bar{X}_{\text {Check }}} \cdot 100=\left(1-\frac{\bar{X}_{\text {Treated }}}{\bar{X}_{\text {Check }}}\right) \cdot 100=(1-R) \cdot 100
$$

$C$ is a commonly reported measure of fungicide effectiveness $(24,25)$ which contains the same information found in $R$. The meta-analysis was based on the natural $\log$ of $R$, $L=\ln (R)=\ln \left(\bar{X}_{\text {Treated }} / \bar{X}_{\text {Check }}\right)=\ln \left(\bar{X}_{\text {Treated }}\right)-\ln \left(\bar{X}_{\text {Check }}\right)$, as the effect size.

An effect size is any statistic (e.g., correlation coefficient, mean difference, standardized difference, regression coefficient, or odds ratio) that can be used to evaluate the overall effect of some predetermined set of treatments or the strength of the relationship between variables $(28,33)$. $L$ was used instead of $R$ or $C$ for statistical reasons. Specifically, the logarithm linearizes the ratio metric, treating deviations of the numerator and denominator equally. Moreover, $L$ typically has closer to a normal distribution than $R$ (or $C$ ), and there is a simple formula for the approximate variance of $L$ that is applicable under small sample sizes (20). The meta-analytic procedures used herein are based on the assumption that the effect sizes are normally distributed. Subscripts are added to $L$ (or $R$ or $C$ ) to refer specifically to index and DON results ( $L_{I N D}$ and $L_{D O N}$ ), when appropriate. When used without a subscript, $L$ (or $R$ or $C$ ) refers generally to either of the variables.

A random-effects meta-analysis was performed to estimate the overall mean effect sizes $\left(\bar{L}_{D O N}\right.$ and $\left.\bar{L}_{I N D}\right)$ and to determine the variability in effect sizes among studies. Study was considered a random effect, and separate meta-analyses were performed for $L_{I N D}$ and $L_{D O N}$. Random-effects models were fitted in PROC MIXED of SAS (SAS Institute, Cary, NC) using maximum likelihood, as described elsewhere $(52,63,67,69)$. Following standard meta-analytical procedures $(28,33)$, studies were weighted in inverse proportion to their sampling variances (within-study variances). The within-study variance ( $V$ ) for IND or DON for these fungicide trials is the residual variance (mean square error) from an analysis of variance (ANOVA) of the effects of treatment on disease or toxin. Where the original data 
were available, this variance was calculated directly from an ANOVA. When only the means and the least significant difference (LSD) were available, $V$ was calculated for a single study based on the definition of the LSD as

$$
V=\frac{n \cdot(L S D / 1.96)^{2}}{2}
$$

where $n$ is the number of replications of each treatment (generally, $n=4$ ). Where the LSD was not available, $V$ was estimated based on the observed relationship between $V$ and mean IND or DON $(\overline{\bar{X}})$ values across 55 studies for IND and 48 studies for DON. That is, for the studies with observed $V$ and $\overline{\bar{X}}$, a power-law model (6) was fitted to the data using least squares. The model is written as $\ln (V)_{i}=a+b \ln (\overline{\bar{X}})_{i}$, where the $i$ subscript indicates the $i$ th study, and $a$ and $b$ are parameters. Note that the double bar denotes the average of mean DON or IND across the two treatments (tebuconazole-treated and untreated check) for a given study. The power-law model provided highly significant fits to sampling variance for IND $(F$ statistic $=127.0, P<0.0001)$ and DON $(F$ statistic $=388.4, P<0.0001)($ P. A. Paul and L. V. Madden, unpublished data). Based on the estimates of $a$ and $b$ across all studies, and observed mean IND or DON for each study, $V$ was predicted for studies with missing variance information. Following Hedges et al. (20), the sampling variance for the $\log$-ratio, $L$, of a single study was calculated by

$$
s^{2}=V \cdot\left(\frac{1}{n \cdot \bar{X}_{\text {Treated }}^{2}}+\frac{1}{n \cdot \bar{X}_{\text {Check }}^{2}}\right)
$$

The weight is given by $1 / s^{2}$.

The random effects model can be written as $L_{i} \sim N\left(\mu, s_{i}^{2}+\sigma^{2}\right)$, where $L_{i}$ is the log-ratio for the $i$ th study $(i=1, \ldots, k), \sim N(\bullet)$ indicates a normal distribution, $\mu$ is the expected value of $L$ (mean effect size), $\sigma^{2}$ is the between-study variance, and $s_{i}^{2}$ is the withinstudy (sampling) variance for the $i$ th study (determined before the meta-analysis). The estimate of $\mu$ equals $\bar{L}_{D O N}$ or $\bar{L}_{I N D}$. A standard normal test statistic, $Z(20,28,33)$, was used to determine whether the effect sizes $\left(\bar{L}_{D O N}\right.$ and $\left.\bar{L}_{I N D}\right)$ were significantly different from zero. Standard errors of $\bar{L}_{D O N}$ and $\bar{L}_{I N D}$ were determined by PROC MIXED based on mixed model theory (34) and used to determine the $95 \%$ confidence intervals around $\bar{L}_{D O N}$ and $\bar{L}_{I N D}$, as described elsewhere $(20,28,33)$. The standard errors of $\bar{L}_{D O N}$ and $\bar{L}_{I N D}$ are functions of the between-study variance and the within-study variances (69).

Mean response ratios and confidence intervals were determined by back-transforming $\bar{L}_{D O N}$ and $\bar{L}_{I N D}$, and back-transforming the limits of the confidence intervals for $\bar{L}_{D O N}$ and $\bar{L}_{I N D}$. For example, $\bar{R}_{D O N}=\exp \left(\bar{L}_{D O N}\right)$. From the response ratios, percent control $(C)$ was determined using equation 2 . It should be noted that increasing $C$ results in decreasing $R$ (or $L$ ).

Moderator variables. The random-effects meta-analysis was expanded to evaluate the influence of wheat type, Fusarium head blight and DON levels, and year on the overall mean log ratios (effect sizes). Wheat type and mean IND $\left(\bar{X}_{I N D}\right)$ and DON $\left(\bar{X}_{D O N}\right)$ for the untreated check were used to group studies into categories. Studies were categorized as spring and winter wheat studies based on their location and the wheat type used. Using IND thresholds of 2 and $15 \%$ and DON thresholds of 1 and $10 \mathrm{ppm}$, studies were grouped into three categories on the bases of mean DON and IND levels. An index of $2 \%$ corresponds to a mean incidence of approximately $14 \%$ (53), and is generally consistent with what is considered an epidemic in some Fusarium head blight risk assessments (50). An index of $15 \%$ was considered to be a high value, and corresponds to the estimated mean level of disease across UFTs at which expected DON $=5 \mathrm{ppm}$ (U.S. Food and Drug Administration [FDA] advisory level for DON in grain and grain byproducts destined for animals other than cattle and chicken), based on a meta-analysis of the relationship between IND and DON (56). A DON level of 1 ppm repre- sents the FDA advisory level for DON in wheat products destined for human consumption, whereas $10 \mathrm{ppm}$ represents the FDA advisory level for DON in grain and grain byproducts destined for consumption by cattle and chicken. Based on mean IND, studies were categorized as (i) studies with $\bar{X}_{I N D} \leq 2 \%$; (ii) studies with $\bar{X}_{I N D}$ between 2 and 15\%; and (iii) studies with $\bar{X}_{I N D} \geq 15 \%$. Similarly, on the bases of mean DON, studies were grouped into those with (i) $\bar{X}_{D O N}<1 \mathrm{ppm}$; (ii) $\bar{X}_{D O N} \geq 1$ and $<10 \mathrm{ppm}$; and (iii) $\bar{X}_{D O N} \geq 10 \mathrm{ppm}$. In a separate analysis, the effect of year on the $\log$ response ratios was evaluated to determine whether the overall percent control of IND and DON changed over time. Here, year was used as a continuous moderator variable.

The moderator variables (wheat type, IND level, DON level, and year) were considered fixed effects; thus, the overall metaanalytical model was a mixed-effects model. A separate metaanalysis was performed for each effect size and for each moderator variable. Models were fitted in PROC MIXED, using the same weights as above, to determine whether these factors significantly affected the effect sizes and to estimate separate mean effect sizes for each level of the moderator variable. The model was identical to that described for models fitted without moderator variables, except that the mean effect size was decomposed into terms for each level of the moderator variable. That is, $\mu$ was no longer a constant, but a linear combination of effects of the moderator variables. Linear contrasts were used to estimate mean effect sizes (or differences of mean effect sizes) for levels of the moderator. Back-transformations followed by the application of equation 2 were used to obtain mean percent control and $95 \%$ confidence intervals for percent control. Significance of moderator variables on the effect sizes was determined using chi-square tests $(28,33)$ based on the linear contrasts.

\section{RESULTS}

Fusarium head blight intensity and DON content. Based on the mean level of disease in the untreated check plots, mean Fusarium head blight IND was generally very similar between spring and winter wheat studies (Fig. 1). Mean IND ranged from 0.10 to $50.65 \%$ for spring wheat studies, and from 0.00 to $54.70 \%$ for winter wheat studies. Fifty percent of the spring and winter wheat studies had mean IND in the untreated control plot ranging between 5 and $26 \%$ and between 2 and 22\%, respectively. Averaging across spring and winter wheat studies, overall mean IND in tebuconazole-treated plots was similar among spring and winter wheat studies (approximately 9\%) and lower than in the untreated check plots. Fifty percent of the spring wheat studies had mean IND between 2 and $12 \%$ in tebuconazole-treated plots, whereas $50 \%$ of the winter wheat studies had mean IND between 1 and $15 \%$ (Fig. 1).

DON levels were within a narrower range in spring wheat studies than in winter wheat studies (Fig. 1). For both the tebuconazoletreated plots and the untreated check plots, mean DON ranged from approximately 0.5 to $19 \mathrm{ppm}$ for spring wheat studies. For winter wheat studies, the range of mean DON was between 0.00 and $34.9 \mathrm{ppm}$. However, values of DON over approximately $20 \mathrm{ppm}$ in winter wheat studies were outliers (Fig. 1). Among spring wheat studies, $50 \%$ had mean DON between 2.2 and $10.2 \mathrm{ppm}$ in the untreated check and between 1.5 and $7.5 \mathrm{ppm}$ in the tebuconazoletreated plots. The corresponding ranges for winter wheat studies were 0.8 to 10.5 and 0.7 to $9.0 \mathrm{ppm}$ for the untreated check and tebuconazole-treated plots, respectively.

Treatment difference, percent control, and response ratio. The difference in mean IND between the untreated check and the tebuconazole treatment $\left(\bar{X}_{\text {Check }}-\bar{X}_{\text {Treated }}\right)$ ranged from -6.77 to 33.80 (Fig. 2A), and the difference in mean DON between the two treatments ranged from -3.9 to 9.50 (Fig. 2B). Fifty percent of the studies had differences in mean IND between 0 and $15 \%$, and $82 \%$ had differences in mean DON between 0 and $6 \mathrm{ppm}$. 
Approximately $9 \%$ of the studies had numerically higher mean IND for the tebuconazole treatment than for the untreated check, that is, a negative difference between the two treatments. Mean DON was numerically higher for the tebuconazole treatment than for the untreated check in $16 \%$ of the studies. Studies with negative differences in mean IND and mean DON between the check and the tebuconazole treatment had correspondingly negative percent control of the two measures of Fusarium head blight. Note that the comparisons here were not formal statistical results, but simple summaries of the distribution of study results.

Percent control as determined by IND was between 0 and 50 in $55 \%$ of the studies, (Fig. 2C); in $72 \%$ of the studies, the percent control as determined by DON was between 0 and 50 (Fig. 2D). By definition (equation 2), studies with negative percent control, percent control between 0 and 50, and percent control between 50 and 100 had corresponding response ratios $(R)$ greater than 1 (or $L>0$ ), between 0.5 and 1 (or $-0.69<L<0$ ), and between 0 and 0.5 (or $L<-0.69$ ), respectively (Fig. $2 \mathrm{E}$ and F).

Meta-analysis and influence of moderator variables. For both IND and DON, the overall mean log-transformed response ratio $(\bar{L})$ was significantly different from zero, based on the standard normal test of the meta-analysis $(P<0.001$, Table 1$)$. The estimated $\bar{L}_{I N D}$ was -0.52 , whereas $\bar{L}_{D O N}$ was -0.24 . This corresponded to an overall mean (expected) percent control $(\bar{C})$
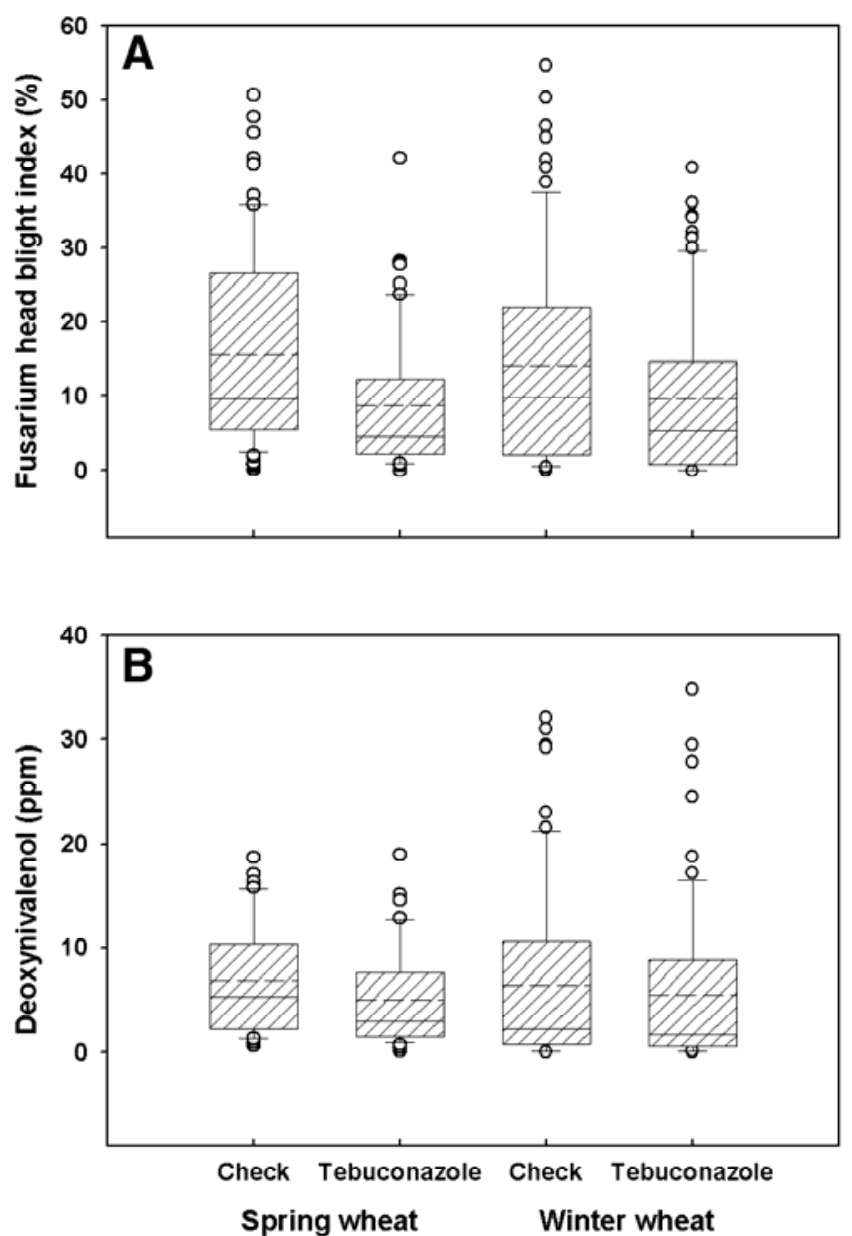

Fig. 1. Box plots summarizing A, distribution of mean Fusarium head blight index (IND $=$ mean percentage of diseased spikelets per spike); and $\mathbf{B}$, deoxynivalenol content of harvested wheat grain (parts per million) for tebuconazole-treated and untreated check plots from winter and spring wheat trials. The broken and solid lines within the box represent the mean and median, respectively, whereas the top and bottom lines of the box represent the 75th and 25th percentiles of the data, respectively. Vertical bars extending beyond the boxes represent the 10th and 90th percentiles, and circles indicate outliers. across all studies of 40.3 and $21.6 \%$ for IND and DON, respectively. The width of the $95 \%$ confidence interval for percent control was 8.92 for $\bar{C}_{I N D}$ and 8.57 for $\bar{C}_{D O N}$.

The estimated between-study variances for $\bar{L}_{I N D}$ and $\bar{L}_{D O N}$ $\left(\hat{\sigma}_{I N D}^{2}=0.126\right.$ and $\hat{\sigma}_{D O N}^{2}=0.037$ ) were significantly different from zero, based on a standard normal test. The impact of the nonzero between-study variances can be seen by the estimated standard error of $L\left[\operatorname{se}\left(\bar{L}_{I N D}\right)\right.$ and $\left.\operatorname{se}\left(\bar{L}_{D O N}\right)\right]$ in Table 1 , which are functions of the between- and within-study variances (69). If one assumed that these between-study variances were, in fact, zero (a situation obtained by conducing a fixed-effects meta-analysis), the standard errors would be incorrectly estimated as 0.0161 for IND and 0.0163 for DON. These values were about half the calculated standard-error values in Table 1 that were determined by utilizing the nonzero between-study variances (as well as the within-study variances) indicated by the data. Using a standard error that is too small results in confidence interval for effect size (and corresponding percent control) that is too narrow.

Based on chi-square tests, all the moderator variables evaluated in this study, with the exception of year, significantly effected $\bar{L}_{I N D}$ and $\bar{L}_{D O N}$. Both effect sizes were influenced by wheat type $(P<0.005$, Table 2$)$. Spring wheat studies had significantly lower $\bar{L}_{I N D}$ and $\bar{L}_{D O N}$, and correspondingly higher $\bar{C}_{I N D}$ and $\bar{C}_{D O N}$ than winter wheat studies. $\bar{C}_{I N D}$ was 46.07 for spring wheat compared with 32.89 for winter wheat (a difference in percent control of 13.18), whereas $\bar{C}_{D O N}$ was 28.45 for spring wheat compared with 16.05 for winter wheat (a difference in percent control of 12.40). The width of the $95 \%$ confidence interval around $\bar{C}_{I N D}$ was higher for winter wheat studies than spring wheat studies, whereas the width of the $95 \%$ confidence interval around $\bar{C}_{D O N}$ was similar (approximately 11.5) for the studies conducted on the two wheat types.

When categorizing studies based on mean disease index $\left(\bar{X}_{I N D}\right)$, studies with $\bar{X}_{I N D}$ between 2 and $15 \%$ had significantly $(P=0.023)$ lower $\bar{L}_{I N D}$, and correspondingly higher $\bar{C}_{I N D}$, than studies with $\bar{X}_{I N D} \leq 2 \%$ (Table 3 ). Pair-wise differences in $\bar{L}_{I N D}$ between other combinations of studies were not significantly different from zero $(P>0.05)$. The corresponding difference in $\bar{C}_{I N D}$ between studies with $\bar{X}_{I N D}$ between 2 and $15 \%$ and those with $\bar{X}_{I N D} \leq 2 \%$ was $25 \%$. The width of the $95 \%$ confidence interval around $\bar{C}_{I N D}$ was narrowest for studies with $\bar{X}_{I N D}$ between 2 and $15 \%$ and widest for studies with $\bar{X}_{I N D} \leq 2 \%$. The wider interval for the latter group of studies reflected the relatively small number of studies considered in this category and the large sampling variance when the denominator of the response ratio was close to zero (equation 4). Because of the high variability in the low index category and lack of significant difference in effect size between two of the categories, the global significance level $(P$ value) for the effect of index was slightly above $0.05(P=0.07)$.

The effect of DON level on $\bar{L}_{D O N}$ was statistically significant $(P=0.003$, Table 3$)$. Studies with $\bar{X}_{D O N}$ between 1 and $10 \mathrm{ppm}$ had lower $\bar{L}_{D O N}$, and correspondingly higher $\bar{C}_{D O N}$ than studies with $\bar{X}_{D O N}<1 \mathrm{ppm}$ and those with $\bar{X}_{D O N} \geq 10 \mathrm{ppm}$. However, the difference in $\bar{L}_{D O N}$ between studies with $\bar{X}_{D O N}$ between 1 and $10 \mathrm{ppm}$ and those with $\bar{X}_{D O N} \geq 10 \mathrm{ppm}$ was not significantly different from zero $(P=0.121) . \bar{C}_{D O N}$ was $28.8 \%$ higher in studies with $\bar{X}_{D O N}$ between 1 and $10 \mathrm{ppm}$ than in studies with $\bar{X}_{D O N}<1 \mathrm{ppm}$, and $6.75 \%$ higher in studies with $\bar{X}_{D O N}$ between 1 and $10 \mathrm{ppm}$ than in studies with $\bar{X}_{D O N} \geq 10 \mathrm{ppm}$. $\bar{C}_{D O N}$ was negative for studies with $\bar{X}_{D O N}$ below $1 \mathrm{ppm}$. This latter group of studies had the widest confidence interval around $\bar{C}_{D O N}$, reflecting the large sampling variance when the denominator of the response ratio was close to zero.

Year of the study did not have a significant effect on $\bar{L}_{I N D}$ and $\bar{L}_{D O N}(P>0.10)$. Thus, there was no evidence of overall trend of increasing or decreasing percent control of FHB or DON in these studies. 
Relative to the model fitted without moderator variables, most of the models fitted after the inclusion of moderator variables had only marginally smaller between-study variances for both $\bar{L}_{I N D}$ and $\bar{L}_{D O N}$ (data not shown). Moderator variables explained between 8 and $11 \%$ of the between-study variance for $\bar{L}_{I N D}$ and between 7 and $10 \%$ of the between-study variance for $\bar{L}_{D O N}$. Thus, even when a moderator variable had a significant effect, there remained considerable unexplained variability among studies. Inclusion of more than one moderator variable in the model at the same time had little effect on the between-study variance estimates, probably because of the intercorrelation of the variables (L. V. Madden, unpublished data).

Probability of a positive percent control and a percent control $>50 \%$. Based on the mean effect size $\left(\bar{L}_{I N D}, \bar{L}_{D O N}\right.$, or
$\operatorname{IND}(k=139)$

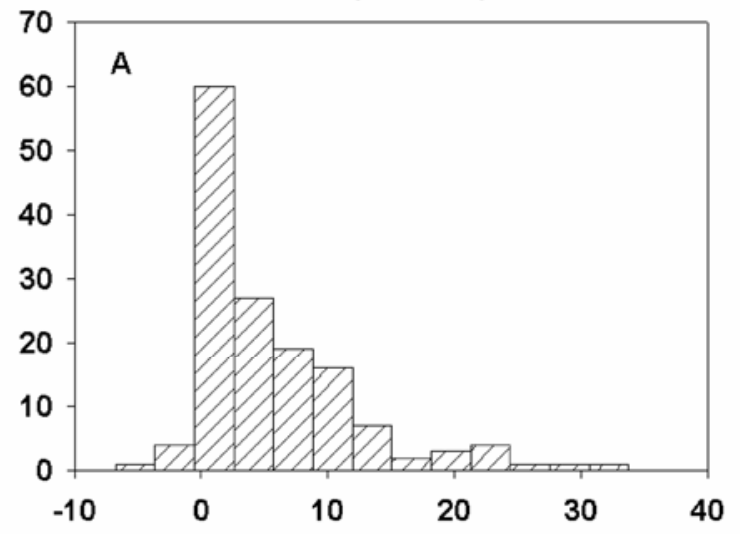

$\operatorname{DON}(k=101)$

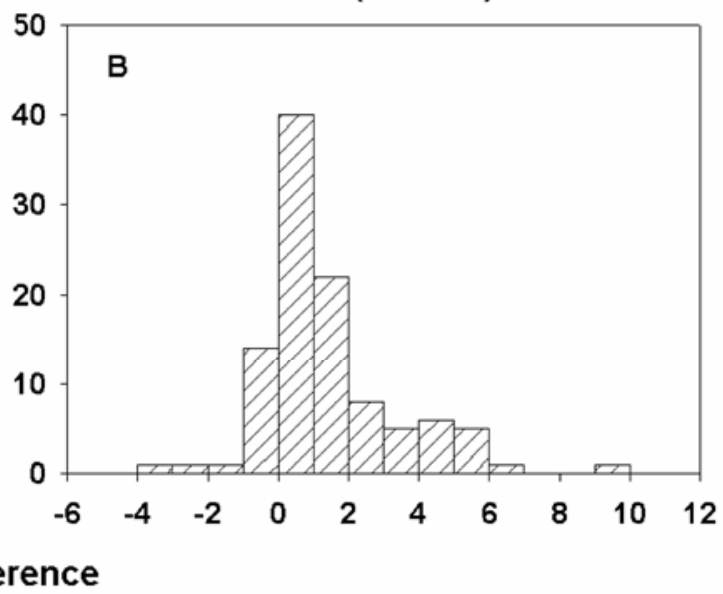

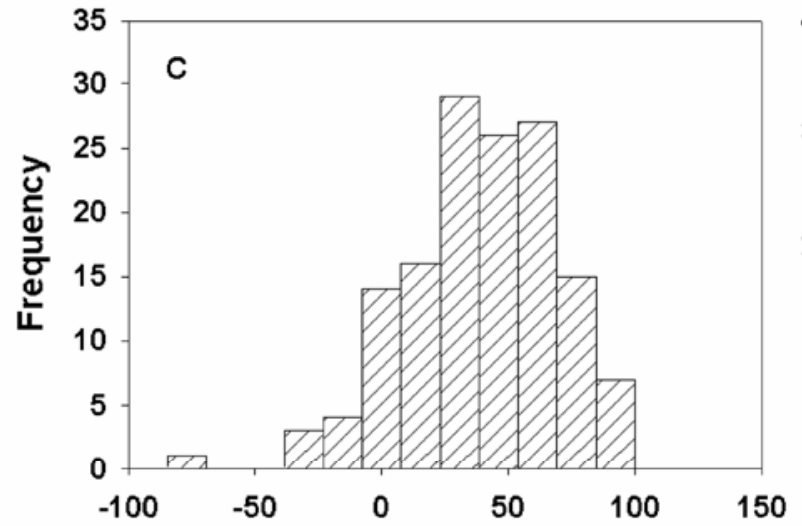

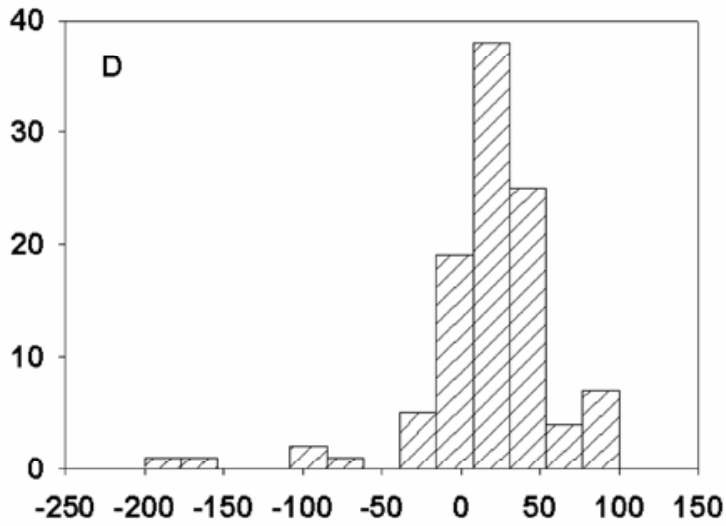

Percent control
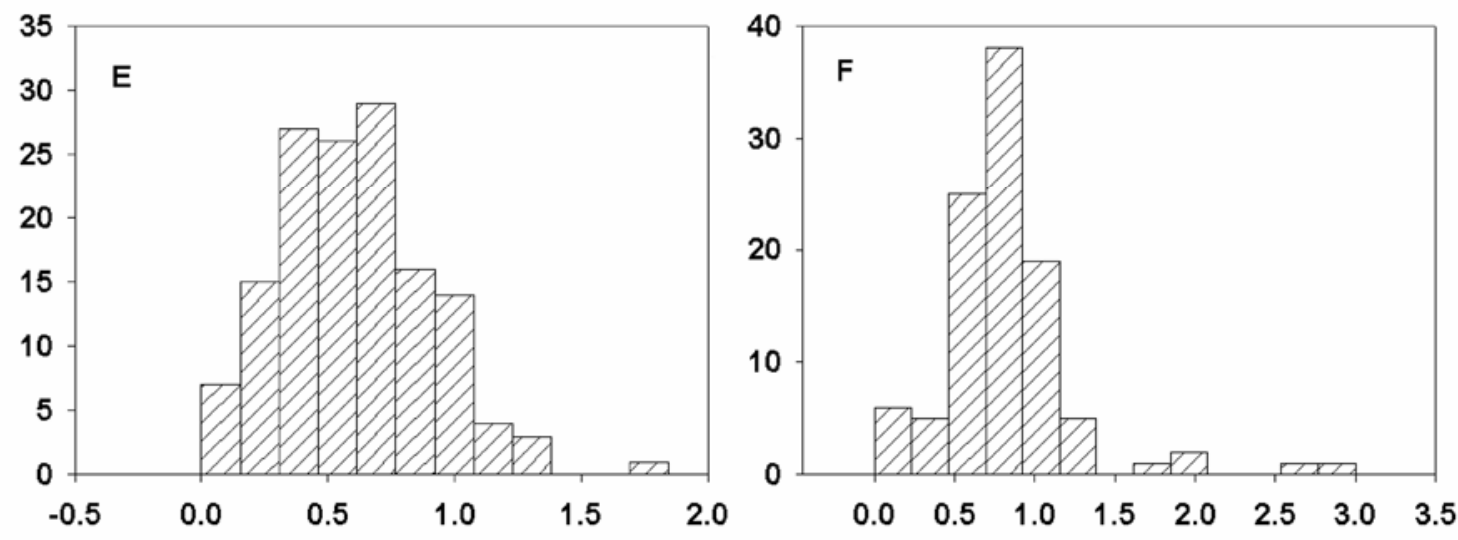

Response ratio

Fig. 2. A and $\mathbf{B}$ show the frequency distribution of difference between means for tebuconazole-treated and untreated check plots; $\mathbf{C}$ and $\mathbf{D}$ show the frequency distribution of the percent control; and $\mathbf{E}$ and $\mathbf{F}$ show the frequency distribution of the response ratio for $\mathbf{A}, \mathbf{C}$, and $\mathbf{E}$, Fusarium head blight index (IND = mean percentage of diseased spikelets per spike), and for $\mathbf{B}, \mathbf{D}$, and $\mathbf{F}$, deoxynivalenol (DON) content of harvested wheat grain (parts per million). $k$ is the number of studies in which the indicated variable was measured. 
in general, $\bar{L}$ ) and the estimated between-study variance $\left(\hat{\sigma}_{I N D}^{2}, \hat{\sigma}_{D O N}^{2}\right.$, or in general, $\left.\hat{\sigma}^{2}\right)$, one can calculate the probability that a new (single) randomly selected study-done in the same way as the studies used in this analysis-will have a positive percent control (equivalent to the probability that $L<0$ or $R<1$ ) (69). The probability is estimated as $p_{+}=\Phi(-\bar{L} / \hat{\sigma})$, where $\Phi(\bullet)$ is the cumulative standard-normal function. As expected, based on the results, $p_{+}$was greater than 0.80 for the general situation (Table 1) without moderator variables, and for all moderator variable categories (Tables 2 and 3), except for the low index (IND1) and DON (DON1) categories. For these latter situations, $p_{+}$was 0.72 for IND1 and only 0.46 for DON1. This is consistent with the results of the $95 \%$ confidence intervals for $\bar{L}$.

The $p_{+}$value is the probability of any value of $C$ above $0 \%$, including very low percentages that would not be considered useful for practical disease control. However, the probability can also be estimated that a new single study will have a percent control greater than some chosen (fixed) value. For instance, the probability that a new study has a percent control greater than $50 \%(L<-0.69)$ is given by $p_{50}=\Phi((-0.69-\bar{L}) / \hat{\sigma})$. For all situations involving DON as the response variable in Tables 1 to $3, p_{50}<0.05$. For index, when moderator variables were not considered, $p_{50}=0.31$ (i.e., $p_{50}=\Phi((-0.69-(-0.52)) / \sqrt{0.126})$ ). For winter and spring wheat, $p_{50}$ was 0.20 and 0.42 , respectively; for IND1, IND2, and IND3 categories, $p_{50}$ was $0.08,0.37$, and 0.29 , respectively. Thus, the likelihood of percent control being above $50 \%$ was remote for DON and also low for disease index. Only for spring wheat or moderate average index (IND2 category) was the probability of such high degree of control greater than 0.35 .

\section{DISCUSSION}

Several individual studies have been conducted to evaluate the effect of different fungicides against Fusarium head blight and DON, with results ranging from no reduction to substantial reductions in both disease and DON levels $(18,21,36,48,62)$. Among the factors likely responsible for such variation in fungicide efficacy among individual studies are (i) inherent differences among fungicides in their effect against Fusarium head blightcausing fungi; (ii) differences in fungicide application rates, timing and methods; (iii) difference in species and aggressiveness of fungal populations; (iv) differences in cultivar susceptibility to Fusarium head blight and DON accumulation; and (v) differences in weather conditions $(8,46)$. The results from fungicide studies suggested that fungicides with triazole chemistry (e.g., tebuconazole) were the most effective against Fusarium head blight and DON, giving the most consistent results $(5,15,22,23,26,41,44,45)$.

To facilitate the evaluation of control of Fusarium head blight and DON by treatment with tebuconazole, a random-effects metaanalysis $(28,33)$ was conducted based on the results of the UFTs of the USWBI. Despite the similarity in protocol among the studies considered, the efficacy of tebuconazole was variable, even though a susceptible cultivar was always used, and the fungicide was applied at (or very close to) a single growth stage with the same active ingredient rate per area. The results from 139 studies analyzed for the effect of tebuconazole on Fusarium head blight IND and 101 studies analyzed for the effect of tebuconazole on DON contamination of harvested grain showed that the percent control of IND and DON ranged from -84.49 to $100 \%$ and -200 to $100 \%$, respectively. The overall mean percent control of IND and DON was 40.3 and $21.6 \%$, respectively (Table 1). Several studies indicated that a single fungicide application also resulted in variable percent control of foliar diseases of wheat, but there is generally a tendency for higher percent control of foliar diseases than those observed for Fusarium head blight $(4,7,9$, 31,32). However, the control percentages observed for Fusarium head blight were consistent with those reported in several individual studies $(21-23,25,36,68)$.

In vitro studies designed to investigate the effects of fungicides on macroconidia of $F$. graminearum and ascospores of G. zeae revealed that tebuconazole-based products were equally effective in limiting germination of both types of spores (68). In addition,

TABLE 1. Log of the response ratio (effect size), percent control, and corresponding statistics for the effect of tebuconazole on Fusarium head blight index (IND) and deoxynivalenol (DON) accumulation in harvested wheat grain

\begin{tabular}{|c|c|c|c|c|c|c|c|c|c|c|}
\hline \multirow[b]{2}{*}{ Variable $^{\mathrm{a}}$} & \multirow[b]{2}{*}{$k^{\mathrm{b}}$} & \multicolumn{6}{|c|}{ Effect size $^{c}$} & \multicolumn{3}{|c|}{ Mean percent control ${ }^{\mathrm{d}}$} \\
\hline & & $\bar{L}$ & $\operatorname{se}(\bar{L})$ & $C I_{L}$ & $C I_{U}$ & $Z$ & $P$ & $\bar{C}$ & $C I_{\mathrm{L}}$ & $C I_{\mathrm{U}}$ \\
\hline IND & 139 & -0.52 & 0.038 & -0.59 & -0.44 & -13.67 & $<0.001$ & 40.32 & 35.69 & 44.61 \\
\hline DON & 101 & -0.24 & 0.028 & -0.30 & -0.19 & -8.85 & $<0.001$ & 21.65 & 17.25 & 25.82 \\
\hline
\end{tabular}

a IND $=$ mean proportion of diseased spikelets per spike, and DON $=$ parts per million.

${ }^{\mathrm{b}}$ Total number of studies used in each analysis (based on the number of studies in which the indicated variable was measured for the Folicur treatment and control).

c $\bar{L}=$ Log-transformed response ratio (equation 1$)$; se $(\bar{L})=$ standard error of $\bar{L}$; lower $\left(C I_{L}\right)$ and upper $\left(C I_{U}\right)=$ limits of the $95 \%$ confidence interval around $\bar{L}$; and $\mathrm{Z}=$ (standard normal) statistic from the meta-analysis of the effect of Folicur on IND and DON. $P=$ probability value (significance level).

d Mean percent control $(\bar{C})$ and lower $\left(C I_{L}\right)$ and upper $\left(C I_{U}\right)$ limits of the $95 \%$ confidence interval for $C$, based on the response ratio $(C=[1-R] \cdot 100$; equation 2$)$, where $R$ is determined from the back-transformation of the log of the response ratio $(L ; R=\exp (L))$. Mean $C(\bar{C})$ corresponds to $\bar{L}$, and confidence limits correspond to the limits for $L\left(C I_{L}\right.$ and $\left.C I_{U}\right)$.

TABLE 2. Log of response ratio (effect size), percent control, and corresponding statistics for the influence of wheat type on tebuconazole effect on Fusarium head blight index (IND) and deoxynivalenol (DON) accumulation in harvested wheat grain

\begin{tabular}{|c|c|c|c|c|c|c|c|c|c|c|}
\hline \multirow[b]{2}{*}{ Variable $^{a}$} & \multirow[b]{2}{*}{ Type $^{\text {b }}$} & \multirow[b]{2}{*}{$k^{\mathrm{c}}$} & \multicolumn{5}{|c|}{ Effect size $^{\mathrm{d}}$} & \multicolumn{3}{|c|}{ Mean percent control ${ }^{\mathrm{e}}$} \\
\hline & & & $\bar{L}$ & $\operatorname{se}(\bar{L})$ & $C I_{L}$ & $C I_{U}$ & $P$ & $\bar{C}$ & $C I_{L}$ & $C I_{U}$ \\
\hline \multirow[t]{2}{*}{ IND } & Winter & 66 & -0.40 & 0.052 & -0.50 & -0.30 & 0.003 & 32.89 & 25.63 & 39.44 \\
\hline & Spring & 73 & -0.62 & 0.050 & -0.72 & -0.52 & 0.003 & 46.07 & 40.49 & 51.13 \\
\hline \multirow[t]{2}{*}{ DON } & Winter & 60 & -0.17 & 0.035 & -0.24 & -0.11 & 0.003 & 16.05 & 10.03 & 21.66 \\
\hline & Spring & 41 & -0.33 & 0.041 & -0.42 & -0.25 & 0.003 & 28.45 & 22.47 & 33.97 \\
\hline
\end{tabular}

a IND = mean proportion of diseased spikelets per spike, and $\mathrm{DON}=$ parts per million

b Data obtained from winter wheat and spring wheat trials.

c Total number of studies used in each analysis (based on the number of studies in which the indicated variable was measured for Folicur treatment and control).

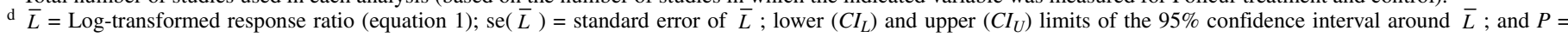
probability value (significance level).

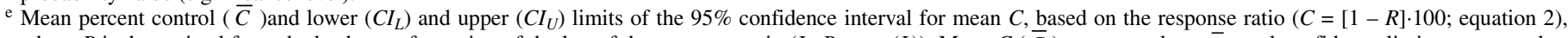
where $R$ is determined from the back-transformation of the log of the response ratio $(L ; R=\exp (L))$. Mean $C(\bar{C})$ corresponds to $\bar{L}$, and confidence limits correspond to the limits for $L\left(C I_{L}\right.$ and $\left.C I_{U}\right)$. 
Ramirez et al. (59) reported that tebuconazole (among other fungicides) inhibited the growth of $F$. graminearum both in vitro and in situ. Hence, the high variability and relatively low percent control of IND and DON being reported herein were probably not due to poor antifungal properties of tebuconazole. Ramirez et al. (59) further reported that, the overall efficacy of tebuconazole (among other fungicides) against $F$. graminearum depended on environmental factors. They observed that fungicides were most effective at reducing fungal growth at $25^{\circ} \mathrm{C}$ rather than at $15^{\circ} \mathrm{C}$ and the effects of fungal isolate and fungicide on growth were only significant at the higher temperature. They compared two strains of $F$. graminearum under controlled conditions and observed that the highest amount of DON produced by one of the strains occurred at a water activity of $0.99 \mathrm{a}_{\mathrm{w}}$ and temperature of $15^{\circ} \mathrm{C}$, whereas for the other strain the corresponding water activity and temperature were $0.97 \mathrm{a}_{\mathrm{w}}$ and $25^{\circ} \mathrm{C}$, respectively. As discussed above, apart from fungicide chemistry and weather conditions, other factors may influence the overall efficacy of chemical control of Fusarium head blight and DON, even when efforts were made (as here) to minimize their impact on the results.

Mesterházy et al. (46) investigated the influence of cultivar resistance and fungal isolate and species aggressiveness on the efficacy of tebucanazole-based (among others) chemicals for control of Fusarium head blight under European conditions. They observed that fungicide, cultivar, fungal isolate, and two-way interactions between these factors significantly affected disease and DON level. Of note were the significant interaction effects of cultivar and fungicide and isolates and fungicide on Fusarium head blight and DON, suggesting that the relative efficacy of the fungicides tested was influenced by cultivar susceptibility and pathogen aggressiveness. Fungicide efficacy against Fusarium head blight, DON, and Fusarium-damaged kernels was generally greater for resistant cultivars than susceptible ones.

In the UFTs evaluated herein, all cultivars used to evaluate fungicide efficacy were considered to be susceptible to Fusarium head blight. However, resistance to $F$. graminearum is quantitative and complex (3), with several different types of resistance reported (43), but not completely characterized. The relative level of susceptibility may have been different across locations in any given year of this investigation. In addition, isolates of $F$. graminearum differ in their aggressiveness and ability to produce DON $(17,47)$. Hence, for a similar level of fungal colonization, the expression of visual symptoms of Fusarium head blight and the accumulation of DON may have differed across studies as a function of differences in host susceptibility, pathogen aggressiveness, and DON-producing ability.

Slight variation in timing of tebuconazole application also may have been accountable for the moderate and variable percent control of IND and DON. Although research suggests that midanthesis is the optimal growth stage for tebuconazole application $(12,37,68)$, flowering time varies among plants in the same plot or field, among tillers of the same plant, and even among spikelets on the same spike (10). The duration of anthesis in any given plot may be very short ( 2 to 3 days) or may be extended for several days ( 7 to 10 days). This poses a serious challenge for the correct timing of fungicide application and the evaluation of degree of control. A clustered sampling approach is often used for Fusarium head blight quantification, where all spikes within a given area or length of row are assessed. The reported disease level (IND, for example) represents the average intensity across all spikes within the sample, irrespective of whether they were sprayed before, at, or after anthesis. Similarly, standard determination of DON at harvest is based on a bulked sample of a small quantity of groundup seeds, likely originating from spikes that were at slightly different development stages at the time of fungicide application. Thus, measured DON and IND in tebuconazole-treated plots in the studies were composite values corresponding to spikes that varied somewhat in phenological stage at the time of fungicide application.

Tebuconazole was more effective in limiting disease increase (as IND) than DON. In 16 of 101 individual studies, DON levels were numerically higher in tebuconazole-treated plots than in the untreated check plots (negative percent control). In eight of these studies, the mean level of DON in the untreated check plot was below $1 \mathrm{ppm}$, and in only 3 of these 16 studies with negative percent control was the absolute value of the difference in DON level between the untreated check plots and tebuconazole-treated plots $\left(\bar{X}_{\text {Check }}-\bar{X}_{\text {Treated }}\right)$ greater than $1 \mathrm{ppm}(1.4,2.8$, and $3.9 \mathrm{ppm}$, respectively) (data not shown). Hence, we believe that any numerically higher levels of DON in treated plots were probably due to sampling errors and inaccuracies in DON quantification (19) at low DON levels rather than to an increase in DON due to tebuconazole application.

Suty and Mauler-Machnik et al. (68), Mesterházy et al. (46), and Homdork et al. (26) all reported that the applications of tebuconazole-based products reduced DON levels in harvested grain. In some instances, fungicide applications have been reported to have no effect on DON accumulation in wheat grain $(36,40,49)$, whereas in other cases DON concentrations have been reported to increase following fungicide application $(16,27,62$, 64,65). Based on laboratory studies, some researchers speculated that increased DON production (in wheat-based media or wheat grain) following fungicide application was a stress response to suboptimal fungal growth conditions (moisture availability and temperature) and sublethal doses of fungicides $(35,59)$. In most of the studies where DON increased following fungicide application

TABLE 3. Log of response ratio (effect size), percent control, and corresponding statistics for the influence of Fusarium head blight index (IND) and deoxynivalenol (DON) levels on tebuconazole effect on IND and DON accumulation in harvested wheat grain

\begin{tabular}{|c|c|c|c|c|c|c|c|c|c|c|}
\hline \multirow[b]{2}{*}{ Variable $^{\mathrm{a}}$} & \multirow[b]{2}{*}{ Level $^{\text {b }}$} & \multirow[b]{2}{*}{$k^{\mathrm{c}}$} & \multicolumn{5}{|c|}{ Effect size $^{\mathrm{d}}$} & \multicolumn{3}{|c|}{ Mean percent control ${ }^{\mathrm{e}}$} \\
\hline & & & $\bar{L}$ & $\operatorname{se}(\bar{L})$ & $C I_{L}$ & $C I_{U}$ & $P$ & $\bar{C}$ & $C I_{\mathrm{L}}$ & $C I_{\mathrm{U}}$ \\
\hline \multirow[t]{2}{*}{ IND } & IND1 & 22 & -0.20 & 0.151 & -0.50 & 0.09 & 0.073 & 18.49 & -10.00 & 39.38 \\
\hline & IND3 & 46 & -0.50 & 0.053 & -0.61 & -0.40 & 0.073 & 39.63 & 33.00 & 45.61 \\
\hline \multirow[t]{3}{*}{ DON } & DON1 & 22 & 0.02 & 0.090 & -0.16 & 0.20 & 0.003 & -02.20 & -22.00 & 14.36 \\
\hline & DON2 & 56 & -0.31 & 0.038 & -0.38 & -0.23 & 0.003 & 26.48 & 20.86 & 31.70 \\
\hline & DON3 & 23 & -0.22 & 0.042 & -0.30 & -0.14 & 0.003 & 19.73 & 12.80 & 26.12 \\
\hline
\end{tabular}

a IND = mean proportion of diseased spikelets per spike, and DON = parts per million.

${ }^{\mathrm{b}}$ Categorical levels of mean (averaged across the untreated check plots) IND and DON: IND1 $=\leq 2 \%$; IND2 $=>2$ and $<15 \%$; IND3 = $\geq 15 \%$; DON1 $=<1$ ppm; $\mathrm{DON} 2=\geq 1$ and $<10 \mathrm{ppm}$; and DON3 $=\geq 10 \mathrm{ppm}$.

$\mathrm{c}$ Total number of studies used in each analysis (based in the number of studies with IND or DON levels within each category).

d $\bar{L}=$ Log-transformed response ratio; $\operatorname{se}(\bar{L})=$ standard error of $\bar{L}$; lower $\left(C I_{\mathrm{L}}\right)$ and upper $\left(C I_{\mathrm{U}}\right)$ limits of the $95 \%$ confidence interval around $\bar{L} . P=$ probability value (significance level).

${ }^{\text {e }}$ Mean percent control $(\bar{C})$ and lower $\left(C I_{\mathrm{L}}\right)$ and upper $\left(C I_{\mathrm{U}}\right)$ limits of the $95 \%$ confidence interval for mean $C$, based on the response ratio $(C=[1-R] \cdot 100$; equation 2), where $R$ is determined from the back-transformation of the log of the response ratio $(L ; R=\exp (L))$. Mean $C(\bar{C})$ corresponds to $\bar{L}$, and confidence limits correspond to the limits for $L\left(C I_{L}\right.$ and $\left.C I_{U}\right)$. 
in the field, strobilurins were applied under European conditions where Fusarium head blight is caused by several species of Fusarium, including the non-DON producing fungus, Microdochium nivale. $M$. nivale does not produce DON and some researchers report that fungicides have differential effects on DONproducing and non-DON-producing species of fungi $(14,64)$.

Limited secondary infection coupled with late-season primary infection (from pathogen-infested residue) may have been responsible for relatively inferior DON control compared with IND control in the analyzed studies. Although the greatest susceptibility is at anthesis $(38,57)$, spike infection may still occur after flowering $(1,11,60)$. Paulitz et al. (57) found that while infection was greatest in those spikes (of greenhouse-grown plants) exposed at Feekes growth stages 10.5 (full spike emergence) and 10.5.4 (end of anthesis) (70\%), infection still occurred in spikes exposed at medium milk (30\%), late milk (15\%), and soft dough (5\%) growth stages. Because of the high inoculum density in the studies, infections considerably after fungicide application were likely common, resulting in the possible increase in fungal biomass, without the appearance of visual symptoms of the disease at the time of disease assessment. Additionally, DON may still accumulate through grain maturation growth stages, three or more weeks after fungicide application. The biomass of tricothecene-producing fungi is positively related to DON content of harvested wheat grain $(14,47,70)$. Similarly, Lacey et al. (29) demonstrated that wheat spikes inoculated with $F$. culmorum at the late milk (Feekes GS 11.1) to early dough (Feekes GS 11.2) plant growth stage (close to the time visual assessments were commonly made) produced small amounts of DON in the absence of visual symptoms.

Tebuconazole was more effective against both IND and DON in spring wheat studies than in winter wheat studies. Even though susceptible cultivars were planted in all studies considered, observations in North Dakota suggest that spring wheat cultivars were probably less susceptible than winter wheat cultivars (M. P. McMullen, unpublished data). This may have been partly responsible for higher percent control in spring wheat than in winter wheat. In addition, since plots were artificially inoculated in most trials, irrespective of the wheat type, higher percent control in spring than in winter wheat studies was most likely due to differences in weather conditions between the two wheat-growing regions and to differences in flowering characteristics between spring and winter wheat classes. Weather conditions affect inoculum production and infection, and the wheat-growing season is usually warmer and the grain-filling period shorter in spring wheat areas than in winter wheat areas. Hershman and Milus (24) speculated that the overall higher percent control of Fusarium head blight and DON in spring wheat than in winter wheat in 2003 was probably due to generally higher disease pressure in winter wheat areas than in spring wheat areas during that year, and to the typically longer grain-filling period in winter wheat areas than in spring wheat areas. However, unlike the observation made by Hershman and Milus (24), mean disease intensity (averaged across studies within each wheat type) for the current multiyear data set was similar for winter and spring wheat. Longer grain-filling periods in winter wheat areas would require fungicides to protect spikes for a longer time (24), and could potentially increase the prospect of late-season primary infection and secondary infections occurring five or more days after fungicide application, when fungicides have been shown to be less effective (68). In addition to shortening the grain-fill period, and consequently, the time required for fungicides to protect spikes, warmer conditions in spring wheat areas may have improved fungicide efficacy, since tebuconazole has been shown to be more effective at reducing fungal growth under warmer than cooler conditions (59).

The results in Tables 1 and 2 represent the (estimated) overall $\log$ response ratios $\left(\bar{L}_{I N D}\right.$ and $\left.\bar{L}_{D O N}\right)$ and percent controls $\left(\bar{C}_{I N D}\right.$ and $\bar{C}_{D O N}$ ) that can be expected (i.e., the average responses), where any value of IND or DON is possible, whenever one applies tebuconazole at growth stage 10.5.1 to susceptible wheat cultivars grown under fairly controlled crop production and management practices. Sometimes the fungicide was applied when disease would have been absent or very low without the fungicide, and sometimes the fungicide was applied when disease would have been moderate or very high without the chemical. As shown with the moderator variable analysis in Table 3, expected percent control did depend on the magnitude of IND and DON, which is partial support for the conclusion of Hershman and Milus (24) that disease level may affect disease-response results. However, the lowest mean percent control was achieved for studies with mean IND and DON in the lowest categories, that is, for studies with $\bar{X}_{I N D} \leq 2 \%$ and $\bar{X}_{D O N}<1 \mathrm{ppm}$, respectively. Variability was also high for this category. For instance, the standard errors of $\bar{L}_{I N D}$ and $\bar{L}_{D O N}$ were higher-and the widths of the $95 \%$ confidence intervals were wider-for studies with low disease or toxin than for studies with higher levels of disease or toxin. The confidence interval for percent control included 0 for IND and DON, indicating that one would not predict, on average, a discernible benefit from tebuconazole application for this category. The lower probability of a positive percent control $\left(p_{+}\right)$for an individual study with very low disease or DON, compared with all other moderator variable situations considered, supports this conclusion. This lack of control, on average, for the low disease or toxin situations is not surprising since there would be little disease or toxin to control.

For studies with $\bar{X}_{I N D} \leq 2 \%$, the observed range of $C_{I N D}$ was between -84.48 and $100 \%$, and for studies with $\bar{X}_{D O N}<1 \mathrm{ppm}$, the range of $C_{D O N}$ was between -200 and $100 \%$. Such high variability (and consequently low precision) was at least partially due to the imprecision associated with DON and disease measurements (the variance of a ratio [or log ratio] is very large when the denominator is near 0 (20). By the nature of the metaanalysis $(20,28,33)$, these high-variability studies contributed very little to the overall expected effect sizes (log ratios or percents control) across all disease or DON levels. The highest percent controls were found for intermediate levels of IND (IND2; 2 to $15 \%)$ and DON (DON2; 1 to $10 \mathrm{ppm})$. At very large IND (>15\%) and DON (>10 ppm) values there was some evidence, especially for DON, that expected percent control declined relative to that obtained on average for the intermediate category of disease and toxin (Table 3). This was probably due to the inability of the fungicide to prevent all infections or fungal growth (and hence DON production) under these conditions (presumably with high inoculum, and infection-favorable and fungal-growth-favorable conditions). The results in Table 3 suggest that previously reported resistance and pathogen aggressiveness effects on percent control by tebuconazole (46) may have been (at least partially) due to the host and/or pathogen effects on overall level of IND or DON in the studies rather than to biological factors specifically affecting the activity of the fungicide.

Tebuconazole did provide significant control of IND and DON based on the meta-analysis, but it is not clear if the estimated degree of control given in Tables 1 to 3 , is high enough to justify the expense of routinely applying the fungicide to wheat for Fusarium head blight and DON control. Clearly, without some knowledge or prediction of the risk of disease in a given year and location, the fungicide application may result in non-recovered expense for the producer. With soft red winter wheat priced at approximately $\$ 123$ metric $\operatorname{ton}^{-1}\left(\$ 3.36 \mathrm{bu}^{-1}\right)$, a tebuconazole application cost (fungicide and application) of $\$ 37.06 \mathrm{ha}^{-1}$ $\left(\$ 15.00 \mathrm{acre}^{-1}\right)$, and an estimated wheat yield in Ohio of 4.71 metric tons $\mathrm{ha}^{-1}\left(70 \mathrm{bu} \mathrm{acre}^{-1}\right)$, it would take a 0.30 -metric ton $\mathrm{ha}^{-1}$ (4.46 bu acre $\left.{ }^{-1}\right)(6.38 \%)$ yield increase to offset the cost of fungicide application. When price reduction due to poor grain quality and DON contamination $(38,51)$-relative to the diseasefree situation-is factored into this calculation, a greater yield 
increase may be necessary to pay for fungicide application. However, the cost of the disease in terms of reduced yield, separately or in combination with increased DON contamination, can be considerably above $\$ 37 \mathrm{ha}^{-1}$ in some years and locations $(38,51)$. Thus, there is considerable incentive to consider fungicide application as a means of lowering the cost of the disease. Based on percent control of disease index and DON contamination found in this study, tebuconazole is much more likely to be cost effective for spring wheats than winter wheats. In fact, studies conducted in some spring wheat areas (North and South Dakota) have shown that the yield and quality responses due to tebuconazole application for Fusarium head blight and DON control may be high enough in some years to offset application cost and price reductions (M. A. Draper and M. P. McMullen, unpublished data). In addition, our results suggested that the probability of achieving a percent control of $50 \%$ or above $\left(p_{50}\right)$ was higher for spring wheat than for winter wheat. However, the decision to use tebuconazole is clouded by the fact that there was considerable variability in the results obtained, even though standard protocols were followed, and only susceptible cultivars were used under conditions of high inoculum, separately or in combination with environmental conditions highly favoring disease (e.g., irrigation). Thus, the percent control in commercial fields may be different, but is unlikely to be higher, on average, than those reported herein. Moreover, we would anticipate poorer fungicide coverage of spikes with commercial application methods, and poorer timing of the application since it is more difficult to spray multiple fields over large areas during the relatively short anthesis period.

Nevertheless, there are few control tactics that individually can provide fully satisfactory control for Fusarium head blight. For spring wheat there are now some resistant cultivars, but growers do not yet routinely use them, especially when the previous year was Fusarium head blight-free (M. McMullen, unpublished data). With expected percent control below $50 \%$ for both IND and DON, and a low probability of achieving this level of control with fungicide application alone, an integrated approach is clearly needed to reduce IND in order to improve grain quality and to routinely (or reliably) reduce DON below critical threshold levels. The use of any fungicide, including tebuconazole, should be done along with other management practices such as tillage, crop rotation, and resistant cultivars. In addition, applications should only be made when warranted, based on predicted risk of an epidemic occurring. Dill-Macky and Jones (13) and Schaafsma et al. (61) observed that tillage and crop rotation away from corn and wheat reduced both Fusarium head blight intensity and DON. Mesterhazy et al. (46) achieved higher efficacy when fungicides were applied to a moderately resistant cultivar than to a susceptible cultivar. More critical studies are needed to evaluate the efficacy of tebuconazole when used as part of an integrated management program to ascertain the overall percent control of disease and DON.

\section{ACKNOWLEDGMENTS}

Salaries and research support were provided by state and federal funds, including the United States Wheat and Barley Scab Initiative, to the Ohio Agricultural Research and Development Center, The Ohio State University. We thank G. Milus of the University of Arkansas, Fayetteville, for providing some of the data utilized in this study.

\section{LITERATURE CITED}

1. Andersen, A. L. 1948. The development of Gibberella zeae head blight of wheat. Phytopathology 38:595-611.

2. Arthur, J. C. 1891. Wheat Scab. Pages 129-132 in: Indiana Agric. Exp. Stn. Bull. 36.

3. Bai, G., and Shaner, G. 1994. Scab of wheat: Prospects for control. Plant Dis. 78:760-766.
4. Bockus, W. W., and Davis, M. A. 2000. Evaluation of foliar fungicides on winter wheat for control of tan spot, 1999. Fungic. Nematicide Tests 55:333.

5. Boyacioglu, D., Hettiarachchy, N. S., and Stack, R. W. 1992. Effect of three systemic fungicides on deoxynivalenol (vomitoxin) production by Fusarium graminearum in wheat. Can. J. Plant Sci. 72:93-101.

6. Campbell, C. L., and Madden, L. V. 1990. Introduction to Plant Disease Epidemiology. John Wiley \& Sons, New York.

7. Cartwright, R. D., Parsons, C. E., Welch, J., and Dodgen, B. J. 2001. Evaluation of foliar fungicides for control of stripe rust of wheat, 2000. Fungic. Nematicide Tests 56:CF14.

8. Champeil, A., and Fourbet, J. F. 2004. Fusarium head blight: Epidemiological origin of the effects of cultural practices on head blight attacks and the production of mycotoxins by Fusarium in wheat grains. Plant Sci. 166:1389-1415.

9. Chen, X., and Wood, D. A. 2002. Control of stripe rust of spring wheat with foliar fungicides, 2001. Fungic. Nematicide Tests 57:CF03.

10. Cook R. J., and Veseth, R. J. 1991. Wheat Health Management. The American Phytopathological Society, St. Paul, MN.

11. Del Ponte, E. M., Fernandes, J. M. C., and Bergstrom, G. C. 2003. Fusarium head blight and deoxynivalenol accumulation in wheat inoculated at developmental stages from flowering through grain maturation. Pages 129-132 in: Proc. Natl. Fusarium Head Blight Forum, Michigan State Univ., East Lansing.

12. Diaz de Ackermann, M., Kohli, M., and Ibanez, V. 2002. Variations in fungicide application techniques to control Fusarium head blight. Page 62 in: Proc. Natl. Fusarium Head Blight Forum, Michigan State Univ., East Lansing.

13. Dill-Macky, R., and Jones, R. K. 2000. The effect of previous crop residues and tillage on Fusarium head blight of wheat. Plant Dis. 84:7176.

14. Edwards, S. G., Pirgozliev, S. R., Hare, M. C., and Jenkinson, P. 2001. Quantification of trichothecene-producing Fusarium species in harvested grain by competitive PCR to determine efficacies of fungicides against Fusarium head blight of winter wheat. Appl. Environ. Microbiol. 67:1575-1580.

15. El-Allaf, S. M., Lipps, P. E., Madden, L. V., and Johnston, A. 2001. Effect of foliar fungicide and biocontrol agents on Fusarium head blight development and control in Ohio. Pages 49-52 in: Proc. 2001 Natl. Fusarium Head Blight Forum. Michigan State Univ., East Lansing.

16. Ellner, F. M., and Schroer, R. 2000. Effects of fungicides containing strobilurin on mycotoxin production in wheat. Pages 101-102 in: Proc. 6th Eur. Fusarium Seminar, Berlin.

17. Goswami, R. S., and Kistler, H. C. 2005. Pathogenicity and in planta mycotoxin accumulation among members of the Fusarium graminearum species complex on wheat and rice. Phytopathology 95:13971404.

18. Haidukowski, M., Pascale, M., Perrone, G., Pancaldi, D., Campagna, C., and Visconti, A. 2005. Effect of fungicides on the development of Fusarium head blight, yield and deoxynivalenol accumulation in wheat inoculated under field conditions with Fusarium graminearum and Fusarium culmorum. J. Sci. Food Agric. 85:191-198.

19. Hart, L. P., and Schabenberger, O. 1998. Variability of vomitoxin in truckloads of wheat in a wheat scab epidemic year. Plant Dis. 82:625-630.

20. Hedges, L. V., Gurevitch, J., and Curtis, P. S. 1999. The meta-analysis of response ratios in experimental ecology. Ecology 80:1150-1156.

21. Hershman, D. E., Bachi, P. R., TeKrony, D. M., and VanSanford, D. A. 2001. Management of Fusarium head blight in wheat using selected biological control agents and foliar fungicides, 2001. Pages 59-63 in: Proc. 2001 Natl. Fusarium Head Blight Forum. Michigan State Univ., East Lansing.

22. Hershman, D., and Draper, M. 2004. Analysis of 2004 uniform fungicide trials across locations and wheat classes. Pages 318-319 in: Proc. 2nd Int. Symposium on Fusarium Head Blight. Michigan State Univ., East Lansing.

23. Hershman, D. E., and Milus, E. A. 2002. Analysis of the 2002 uniform wheat fungicide and biocontrol trials across locations. Pages 82-87 in: Proc. Natl. Fusarium Head Blight Forum. Michigan State Univ., East Lansing.

24. Hershman, D. E., and Milus, E. A. 2003. Analysis of the 2003 uniform wheat fungicide trials across locations and wheat classes. Pages 76-80 in: Proc. Natl. Fusarium Head Blight Forum. Michigan State Univ., East Lansing.

25. Hershman, D. E., and Milus, E. A. 2003. Performance of Folicur in Fusarium head blight uniform fungicide trials, 1998-2003. Pages 81-82 in: Proc. Natl. Fusarium Head Blight Forum. Michigan State Univ., East Lansing.

26. Homdork, S., Fehrmann, H., and Beck, R. 2000. Effects of field application of tebuconazole on yield, yield components and the mycotoxin content of Fusarium-infected wheat grain. J. Phytopathol. 148:1-6. 
27. Hope, R. J., Colleate, A., Baxter, E. S., and Magan, N. 2000. Interactions between Fusarium culmorum, other contaminant fungi, environmental stress and fungicides, affect growth and deoxynivalenol production in wheat grain. Pages 102-103 in: Proc. 6th Eur. Fusarium Seminar, Berlin.

28. Hunter, J. E., and Schmidt, F. L. 2004. Methods of Meta-Analysis: Correcting Error and Bias in Research Findings. 2nd ed. Sage Publications Inc., Thousand Oaks, CA.

29. Lacey, J., Bateman, G. L., and Mirocha, C. J. 1999. Effects of infection time and moisture on development of ear blight and deoxynivalenol production by Fusarium spp. in wheat. Ann. Appl. Biol. 134:277-283.

30. Large, E. C. 1954. Growth stages in cereals. Plant Pathol. 3:128-129.

31. Lipps, P. E., Mills, D., and Johnston, A. L. 2003. Evaluation of foliar fungicides for control of powdery mildew, Stagonospora blotch and Septoria blotch on wheat in Ohio, 2002. Fungic. Nematicide Tests 59:CF001.

32. Lipps, P. E., Mills, D., and Johnston, A. L. 2004. Evaluation of foliar fungicides for control of powdery mildew, Stagonospora blotch and Septoria blotch on wheat in Ohio, 2003. Fungic. Nematicide Tests 59:CF004.

33. Lipsey, M. W., and Wilson, D. B. 2001. Practical Meta-Analysis. Sage Publications Inc., Thousand Oaks, CA.

34. Littell, R. C., Milliken, G. A., Stroup, W. W., and Wolfinger, R. D. 1996. SAS System for Mixed Models. SAS Institute, Cary, NC.

35. Magan, N., Hope, R., Colleate, A., and Baxter, E. S. 2002. Relationship between growth and mycotoxin production by Fusarium species, biocides and environment. Eur. J. Plant Pathol. 108:685-690.

36. Martin, R. A., and Johnston, H. W. 1982. Effects and control of Fusarium diseases of cereal grains in the Atlantic Provinces. Can. J. Plant Pathol. 4:210-216.

37. McMullen, M., Halley, S., Pederson, J., Moos, J., and Jordahl, J. 2000. Effects of application parameters on control of Fusarium head blight with fungicides. Pages 94-97 in: Proc. Natl. Fusarium Head Blight Forum. Michigan State Univ., East Lansing.

38. McMullen, M., Jones, R., and Gallenburg, D. 1997. Scab of wheat an barley: A re-emerging disease of devastating impact. Plant Dis. 81:13401348

39. McMullen, M., Lukach, J., McKay, K., and Schatz, B. 2002. ND uniform wheat fungicide and biological agent trials, 2002. Pages 97-99 in: Proc. Natl. Fusarium Head Blight Forum. Michigan State Univ., East Lansing.

40. McMullen, M., and Milus, E. 2002. History and accomplishments of the USWBSI uniform fungicide and biological control trials. Page 96 in: Proc. Natl. Fusarium Head Blight Forum. Michigan State Univ., East Lansing.

41. McMullen, M., Milus, G., and Prom, L. 1999. 1999 Uniform fungicide trials to identify products effective against Fusarium head blight in wheat. Pages 64-68 in: Proc. 1999 Natl. Fusarium Head Blight Forum. Michigan State Univ., East Lansing.

42. Menniti, A. M., Pancaldi, D., Maccaferri, M., and Casalini, L. 2003. Effect of fungicides on Fusarium head blight and deoxynivalenol content in durum wheat grain. Eur. J. Plant Pathol. 109:109-115.

43. Mesterházy, Á. 1995. Types and components of resistance against Fusarium head blight of wheat. Plant Breed. 98:25-36.

44. Mesterházy, Á., and Bartók, T. 1997. Effect of chemical control on FHB and toxin contamination of wheat. Cereal Res. Comm. 25:781-783.

45. Mesterházy, A., and Bartók, T. 2001. Fungicide control of Fusarium head blight in wheat. Pages 70-74 in: Proc. 2001 Natl. Fusarium Head Blight Forum. Michigan State Univ., East Lansing.

46. Mesterházy, A., Bartók, T., and Lamper, C. 2003. Influence of wheat cultivar, species of Fusarium, and isolate aggressiveness on the efficacy of fungicides for control of Fusarium head blight. Plant Dis. 87:11071115 .

47. Miller, J. D., Young, J. C., and Sampson, D. R. 1985. Deoxynivalenol and Fusarium head blight resistance in spring cereals. Phytopathol. Z. 113:359-367.

48. Milus, E. A., Hershman, D., and McMullen, M. 2001. Analysis of the 2001 uniform fungicide and biocontrol trials across locations. Pages 7581 in: Proc. 2001 Natl. Fusarium Head Blight Forum Michigan State Univ., East Lansing.

49. Milus, E. A., and Parsons, C. E. 1994. Evaluation of foliar fungicides for controlling Fusarium head blight of wheat. Plant Dis. 78:697-699.

50. Molineros, J., DeWolf, E., Madden, L., Paul, P., and Lipps, P. 2005. Incorporation of host reaction and crop residue level into prediction models for Fusarium head blight. Pages 119-122 in: Proc. 2005 Natl.
Fusarium Head Blight Forum, Milwaukee, WI.

51. Nganje, W. E., Bangsund, D. A., Leistritz, F. L., Wilson, W. W., and Tiapo, N. M. 2004. Regional economic impact of Fusarium head blight in wheat and barley. Rev. Agric. Econ. 26:322-347.

52. Normand, S. L. T. 1999. Tutorial in biostatistics. Meta-analysis: Formulating, evaluating, combining, and reporting. Stat. Med. 18:321-359.

53. Paul, P. A., El-Allaf, S. M., Lipps, P. E., and Madden, L. V. 2005. Relationships between incidence and severity of Fusarium head blight on winter wheat in Ohio. Phytopathology 95:1049-1060.

54. Paul, P. A., Hershman, D., Draper, M., and Madden, L. V. 2005. Effect of fungicides on FHB and DON in wheat - 2005 uniform fungicide trials. Pages 225-229 in: Proc. 2005 Natl. Fusarium Head Blight Forum, Michigan State Univ., East Lansing.

55. Paul, P. A., Lipps, P. E., and Madden, L. V. 2005. Relationship between visual estimates of Fusarium head blight intensity and deoxynivalenol accumulation in harvested wheat grain: A meta-analysis. Phytopathology 95:1225-1236

56. Paul, P. A., Lipps, P. E., and Madden, L. V. 2006. Meta-analysis of regression coefficients for the relationship between Fusarium head blight and deoxynivalenol content of wheat. Phytopathology 96:951-961.

57. Paulitz, T. C., Fernando, W. G. D., and Seaman, W. L. 1997. Susceptibility of wheat heads at different growth stages when exposed to ascospores of Gibberella zeae. Pages 52-32 in: Proc. 1997 Natl. Fusarium Head Blight Forum. Michigan State Univ., East Lansing.

58. Pirgozliev, S. R., Edwards, S. G., Hare, M. C., and Jenkinson, P. 2002. Effect of dose rate of azoxystrobin and metconazole on the development of Fusarium head blight and the accumulation of deoxynivalenol (DON) in wheat grain. Eur. J. Plant Pathol. 108:469-478.

59. Ramirez, M. L., Chulze, S., and Magan, N. 2004. Impact of environmental factors and fungicides on growth and deoxinivalenol production by Fusarium graminearum isolates from Argentinian wheat. Crop Prot. 23:117-125.

60. Reis, E. M., Blum, M. M. C., and Casa, R. T. 1996. Controle quimico de Gibberella zeae em trigo, um problema de deposicao de fungicidas em anteras. Summa Phytopathol. 22:39-42.

61. Schaafsma, A. W., Tamburic-Ilincic, L., and Hooker, D.C. 2005. Effect of previous crop, tillage, field size, adjacent crop, and sampling direction on airborne propagules of Gibberella zeae/Fusarium graminearum, fusarium head blight severity, and deoxynivalenol accumulation in winter wheat. Can. J. Plant Pathol. 27:217-224.

62. Shaner, G., and Buechley, G. 2000. Control of Fusarium head blight of wheat with foliar fungicides. Pages 110-113 in: Proc. 2000 Natl. Fusarium Head Blight Forum. Michigan State Univ., East Lanisng.

63. Sheu, C. F., and Suzuki, S. 2001. Meta-analysis using linear mixed models. Behav. Res. Meth. Ins. 33:102-107.

64. Simpson, D. R., Weston, G. E., Turner, J. A., Jennings, P., and Nicholson, P. 2001. Differential control of head blight pathogens of wheat by fungicides and consequences for mycotoxin contamination of grain. Eur. J. Plant Pathol. 107:421-431.

65. Siranidou, E., and Buchenauer, H. 2001. Chemical control of Fusarium head blight on wheat. J. Plant Dis. Prot. 108:231-243.

66. Stack, R. W. 2003. History of Fusarium head blight with emphasis on North America. Pages 1-34 in: Fusarium Head Blight of Wheat and Barley. K. J. Leonard and W. R. Bushnell, eds. The American Phytopathological Society, St. Paul, MN.

67. Stijnen, T. 2000. Tutorial in biostatistics. Meta-analysis: Formulating, evaluating, combining, and reporting by S-L. T. Normand, Statistics in Medicine, 18, 321-359 (1999). Stat. Med. 19:759-761.

68. Suty, A., Mauler-Machnik, A., and Courbon, R. 1996. New findings on the epidemiology of Fusarium ear blight on wheat and its control with tebuconazole. Pages 511-516 in: Proc. The Brighton Crop Protection Conf.: Pest and Diseases, Vol. 2. Brighton, UK.

69. Van Houwelingen, H. C., Arends, L. R., and Stijnen, T. 2002. Advanced methods in meta-analysis: Multivariate approach and meta-regression. Stat. Med. 21:589-624.

70. Wang, Y. Z., and Miller, J. D. 1988. Effects of Fusarium graminearum metabolites on wheat tissue in relation to Fusarium head blight resistance. J. Phytopathol. 122:118-125.

71. Xu, X.-M., Parry, D. W., Edwards, S. G., Cooke, B. M., Doohan, F. M., Maanen, A., Brennan, J. M., Monaghan, S., Moretti, A., Tocco, G., Mule, G., Hornok, L., Giczey, G., Tatnell, J., Nicholson, P., and Ritieni, A. 2004. Relationship between the incidences of ear and spikelet infection of Fusarium ear blight in wheat. Eur. J. Plant Pathol. 110:959-971. 